\title{
Efficient Removal of Methylene Blue by Fenton-like Reaction using nZVI/GAC Composite as Catalyst
}

\author{
Sihai Hu, Yaoguo $\mathrm{Wu}^{*}$, Hairui Yao, Jianguo Wei and Shuai Zhang \\ Department of Applied Chemistry, School of Science,Northwestern Polytechnical University, Xi'an, Shaanxi, P.R. China \\ ${ }^{*}$ Corresponding author
}

\begin{abstract}
A composite of nano-zerovalent iron (nZVI) supported on granular activated carbon (GAC) was synthesizedthrough adsorption-reduction method, and its performances used as catalyst of Fenton-like were investigated to degrade methylene blue (MB) in model wastewater.Theresults show thathomogeneous dispersion of nZVI was greatly improved after supported on GAC. In comparison, the composite (nZVI/GAC) has higher removal efficiency of $\mathrm{MB}$ than the same amount of nZVI or GAC. Moreover, the pH values increased and leaching iron was reduced after reaction which were help to further processing with lowcost. The useof nZVI/GAC composite provided a selective and viable solution for removing MB from water by Fenton-like reaction.
\end{abstract}

Keywords-Fenton-like; methylene blue (MB); nZVI/GAC catalyst; removal

\section{INTRODUCTION}

Organic pollutants have been widely detected in aquatic environment with the increasing of contamination. Fenton and Fenton-like systems either heterogeneous or homogeneous have been extensively studied in view of their high efficiency, simplicity and environmental friendliness [1]. Nano-zero valent iron (nZVI) is currently of an interest catalyst to decompose hydrogen peroxide $\left(\mathrm{H}_{2} \mathrm{O}_{2}\right)$ to produce hydroxyl radicals $(\cdot \mathrm{OH})$ owing to its high surface and activity in Fenton-like system. However, nZVI is tend to aggregate because of its small size, which decreases the surface area of nZVI and hinders the regeneration of ferrous ions $\left(\mathrm{Fe}^{2+}\right)$, often resulting in the decrease of catalytic degradation efficiency[2]. Thus, it is necessary to modify the features of nZVI. Granular activated carbon (GAC), as a carrier of commonly used support material, has been proved to be effective for increasing dispersion and impeding aggregation of nZVI [3]. Moreover, recent studies have indicated that iron-carbon microelectrolysis system can be formed between AC and iron spontaneously when iron (anode) and AC (cathode) particles are mixed and contact with each other [4-6]. The microelectrolysis can promote the cycle of ferric iron $\left(\mathrm{Fe}^{3+}\right)$ and $\mathrm{Fe}^{2+}$ via acceleration the electron transfer, which is beneficial to improve catalytic degradation efficiency of Fenton-like to organic pollutants[7].

Therefore, in the present study, methylene blue (MB) which always causes waste disposal problems in textile industries was selected as the model pollutant. The composite of GAC supported nZVI (nZVI/GAC) synthesized via adsorptionchemical reduction method was used as heterogeneous catalyst in the Fenton-like system. The performances of the catalyst were evaluated aiming to achieve a high efficient catalyst with low environment effect.

\section{MATERIALS AND MethodS}

The nZVI/GAC composite was prepared by chemical reduction in sodium borohydride solution. First, GAC was adsorption saturated with $\mathrm{Fe}^{2+}$ via mixture of $\mathrm{FeSO}_{4} \cdot 7 \mathrm{H}_{2} \mathrm{O}$ and GAC. Then the saturated GAC was separated and reduced using sodium borohydride solution in $\mathrm{N}_{2}$ atmosphere[8].

The batch experiments were conducted in $250-\mathrm{mL}$ vials placed on a rotary shaker. The temperature and rotate speed were $25^{\circ} \mathrm{C}$ and $120 \mathrm{rmp}$, respectively. Each glass was filled with $50 \mathrm{mg} / \mathrm{L} \mathrm{MB}$ solution $(200 \mathrm{~mL})$ and a certain amount of $\mathrm{H}_{2} \mathrm{O}_{2}$. The initial $\mathrm{pH}$ value was adjusted by $0.5 \mathrm{M} \mathrm{H}_{2} \mathrm{SO}_{4}$. At interval time, the supernatant liquid was collected for $\mathrm{MB}$ and iron concentration analysis after centrifugation for $10 \mathrm{~min}$ at $4500 \mathrm{rmp}$.

X-ray diffraction patterns (XRD) were tested by powder diffractmeter(Bruker D8, Germany). Scanning electron microscopy (SEM)(Tescan, VEGA 3 LMH,Czekh) was used to view the surface characteristics and morphology of nZVI/GAC composite. $\mathrm{MB}$ concentration in aqueous samples was measured by spectrophotometry with wavelength at $665 \mathrm{~nm}$. The leaching total iron was determined by AAS (PERSEE Beijing, China), and the $\mathrm{pH}$ value of the solution was measured by pHS-3C monitor (Shanghai, China).

\section{RESULTS AND DISCUSSION}

\section{A. Structure of $n Z V I / G A C$ Composite}

The XRD pattern and SEM images of nZVI in the absence and presence of GAC are presented in Figure I. As shown in the Figure Ia, the representative peak of zero valent $\left(\mathrm{Fe}^{0}\right)$ at $2 \theta=$ $45^{\circ}$ was observedindicating thatthe main state of iron was $\mathrm{Fe}^{0}$,which was consistent with the results obtained in previous experiment[9]. The peak at $2 \theta=25^{\circ}$ are typically peak of $\mathrm{C} 002$ which confirmed the presence of GAC in the composite. From FigureIb and c, it is obvious that the bare nZVI was liable to be agglomeration due to the high active surface of nanoparticles (Figure Ib). However, as comparison nZVI particles well dispersed on GAC carrier (Figure Ic), illuminating the homogeneous dispersion of nZVI was greatly improved after supported on GAC. This might be a big potential to enhance Fenton-like catalytic efficiency in real application. 

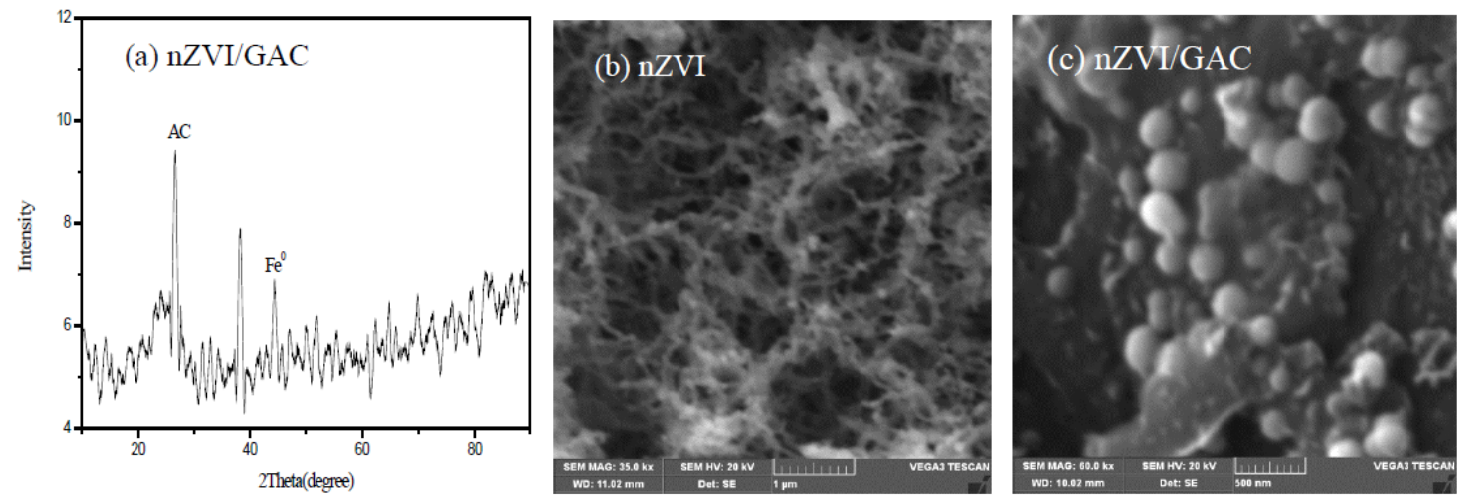

FIGURE I. XRD PATTERN AND SEM IMAGES of nZVI and nZVI/GAC composite

\section{B. MB Removal by $n Z V I / G A C$ Fenton-like}

The removal efficiencyin the presenceof nZVI, GAC, and nZVI/GAC composite was investigated with $50 \mathrm{mg} / \mathrm{L} \mathrm{MB}, 5$ $\mathrm{mmol} / \mathrm{L} \quad \mathrm{H}_{2} \mathrm{O}_{2}, \quad 0.015 \mathrm{~g} / \mathrm{L} \quad$ nZVI,0.5 $\mathrm{g} / \mathrm{L} \quad$ GAC, $\quad 0.5 \mathrm{~g} / \mathrm{L}$ $\mathrm{nZVI} / \mathrm{GAC}$, and initial $\mathrm{pH}$ of 4.02. As shown in Figure II, the removal ratio of $\mathrm{MB}$ for $\mathrm{nZVI}, \mathrm{GAC}$, and nZVI/GAC was 27.1, 41.4, and $84.6 \%$ respectively. It is clear that the higher removal was achieved with nZVI/GAC composite as Fentonlike catalyst. Moreover, the removal ratio for the composite was higher the sum of nZVI and GAC, implying that synergetic effect was existence when association nZVI with GAC in virtue of internal iron-carbonmicroelectrolysis formed spontaneously in such a composite.

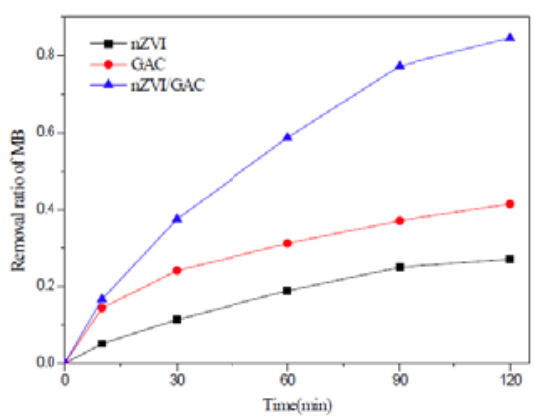

FIGURE II. Changes of Removal ratio to MB

\section{Environmental Effects after Reaction}

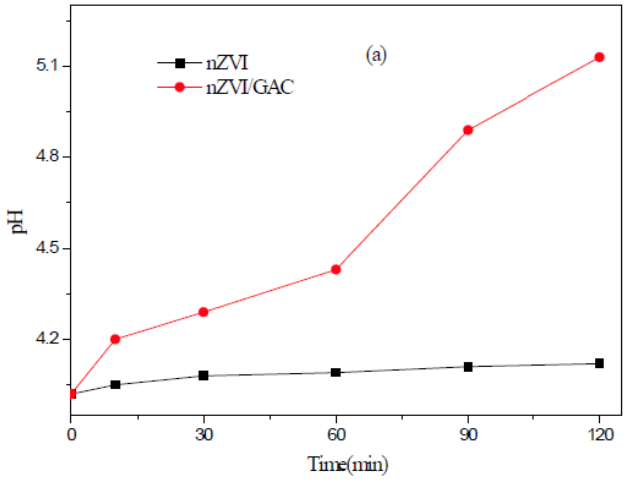

Previous studies show that the efficiency of Fenton reaction is very dependent on $\mathrm{pH}$ values, and an optimum working $\mathrm{pH}$ range is $2.8 \sim 3.2$ for classical Fenton reaction[10].Nevertheless, such a low $\mathrm{pH}$ is not desired for the effluent of Fenton reaction because of the costs of acidificationduring subsequentprocessing and neutralization after treatment. In addition, iron leaching is also a problem that must be considered for Fenton reaction. Thus, environmental effects including $\mathrm{pH}$ and dissolved iron was detected in the process of reaction with 50mg/L MB, $0.5 \mathrm{~g} / \mathrm{L} \mathrm{nZVI} / \mathrm{GAC}, 0.015 \mathrm{~g} / \mathrm{L} \mathrm{nZVI}$, $5 \mathrm{mmol} / \mathrm{LH}_{2} \mathrm{O}_{2}$, and 4.02 of $\mathrm{pH}$, and the results are shown in Figure III. From Figure IIIa, the $\mathrm{pH}$ values slightly increased from 4.02 to 4.12 for $\mathrm{nZVI}$, but for $\mathrm{nZVI} / \mathrm{GAC}$ the $\mathrm{pH}$ values dramatically increased from 4.02 to 5.13. Similarly, the leaching of iron was significantly reduced compared to nZVI individually (Figure III b). Hence, the increase of $\mathrm{pH}$ and decrease in leaching iron are great of advantages for Fentonlike process as cost saving in the water subsequent processing.

FIGURE III. pH values and dissolved iron concentration changes in Fenton-like reaction 


\section{CONCLUSIONS}

This study revealed the potential of nZVI/GAC composite for the removal of MB from aquatic environment. The catalytic effect of Fenton-like was significantly improved as nZVI supported on GAC carrier owing to the internal iron-carbon microelectrolysis. Furthermore, $\mathrm{pH}$ values increase and leaching iron decrease after reaction are more desirable trends for polluted water treatment by Fenton method.

\section{ACKNOWLEDGMENT}

The authors are grateful to the support of National Natural Science Foundation of China (Grant No.41502240; 40872164), Fund for basic research from the Northwestern Polytechnical University (JCY20130145), China geological survey project (12120114056201), and graduate starting seed fund of Northwestern Polytechnical University (Z2015147).

\section{REFERENCES}

[1] Y.Qin, F. H. Song, Z. H. Ai, P. P. Zhang, and L. Z. Zhang, "Protocatechuic acid promoted alachlor degradation in Fe (III) $/ \mathrm{H}_{2} \mathrm{O}_{2}$ Fenton system,” Environ. Sci. Technol., 2015, 49(13), pp. 7948-7956.

[2] S. A.Messele, O. S. G. P.Soares, J. J. M.Órfão, F.Stüber, C. Bengoa, A.Fortuny, A. Fabregat, and J.Font, "Zero-valent iron supported on nitrogen-containing activated carbon for catalytic wet peroxide oxidation of phenol,” Appl. Catal. B: Environ.,2014, 154-155, pp. 329338.

[3] J. N.Xiao, Q. Y.Yue, B. Y.Gao, Y. Y. Sun, J. J.Kong, Y.Gao, Q. Li, and Y.Wang, "Performance of activated carbon/nanoscale zero-valent iron for removal of trihalomethanes (THMs) at infinitesimal concentration in drinking water,” Chem. Eng. J.,2014, 253, pp. 63-72.

[4] X. M.Dou, R. Li, B.Zhao, and W. Y.Liang, “Arsenate removal from water by zero-valent iron/activated carbon galvanic couples,”J. Hazard. Mater.,2010, 182, pp. 108-114.

[5] K.Mackenzie, S.Bleyl, A. Georgi, and F. D.Kopinke, "Carbo-Iron-An Fe/AC composite-As alternative to nano-iron for groundwater treatment,”Water Res.,2012,46, pp. 3817-3826.

[6] J. H.Luo, G. Y. Song, J. Y. Liu, G. G. Qian,and Z. P. Xu, "Mechanism of enhanced nitrate reduction via microelectrolysis at the powdered zero-valent iron/activated carbon interface,” J. Colloid Interf. Sci.,2014, 435, pp. 21-25.

[7] S. H. Hu, H. R. Yao, K. F. Wang, C. Lu, and Y. G. Wu, "Intensify removal of nitrobenzene from aqueous solution using nano-zero valent iron/granular activated carbon composite as Fenton-Like catalys,"Water Air, Soil Poll., 2015, 226(5), pp. 1-13.

[8] Y. G. Wu, M. C. Yang, S. H. Hu, L. Wang,and H. Y. Yao, "Characteristics and mechanisms of 4A zeolite supported nanoparticulate zero-valent iron as Fenton-like catalyst to degrade methylene blue,”Toxico. Enviro. Chem., 2014, 96(2), pp. 227-242.

[9] L.J.Xu and J.L. Wang, "A heterogenous Fenton-like system with naoparticulate zero valent iron for removal of 4 chloro-3-methyl phenol,” J. Hazard. Mater.,2011, 186, pp. 256-264.

[10] D. Bokare and W. Choi, "Review of iron-free Fenton-like systems for activating $\mathrm{H}_{2} \mathrm{O}_{2}$ in advanced oxidation processes," J. Hazard. Mater., 2014, 275, pp. 121-135. 